\title{
Application of mechanistic empirical approach to predict rutting of superpave mixtures in Iraq
}

\author{
Zaynab Qasim ${ }^{1, *}$, Hamed Hamdou ${ }^{2}$, and Namir Alkawaaz ${ }^{3}$ \\ ${ }^{1}$ Building and Construction Engineering Department, University of Technology, Baghdad, Iraq \\ ${ }^{2}$ University of Baghdad, Baghdad, Iraq \\ ${ }^{3}$ University of Al-Mustansiriyah, Baghdad, Iraq
}

\begin{abstract}
In Iraq rutting is considered as a real distress in flexible pavements as a result of high summer temperature, and increased axle loads. This distress majorly affects asphalt pavement performance, lessens the pavement useful service life and makes serious hazards for highway users. Performance of HMA mixtures against rutting using Mechanistic- Empirical approach is predicted by considering Wheel-Tracking test and employing the Superpave mix design requirements. Roller Wheel Compactor has been locally manufactured to prepare slab specimens. In view of study laboratory outcomes that are judged to be simulative of field loading conditions, models are developed for predicting permanent strain of compacted samples of local asphalt concrete mixtures after considering the stress level, properties of local material and environmental impacts variables. All in all, laboratory results were produced utilizing statistical analysis with the aid of SPSS software. Permanent strain models for asphalt concrete mixtures were developed as a function of: number of passes, temperature, asphalt content, viscosity, air voids and additive content. Mechanistic Empirical design approach through the MnPAVE software was applied to characterize rutting in HMA and to predict allowable number of loading repetitions of mixtures as a function of expected traffic loads, material properties, and environmental temperature.
\end{abstract}

\section{Introduction}

Various inconvenient types of distresses regularly impact on the asphaltic paving mixture during its service life. These distresses are caused by construction practices, load, climate, and /or lacking materials. One of the genuine distresses is rutting; or permanent deformation which at last may lead to complete failure of pavement. Such distress will lessen the performance of asphalt pavements, which makes second rate ride quality drivers as well as yields higher life-cycle cost, [1].

FHWA in 2003 described rutting as longitudinal surface depression in the wheel path, which may have associated transverse displacement, [2]. Furthermore, Huang in 1993 stated that the permanent deformation is an imperative factor in design of flexible pavement, [3].

With expansion in activity load and tyre weight, most of the rutting occurs in the upper layers as opposed to that in subgrade. Permanent deformation may likewise start different types of asphalt pavement distress, for example, cracking, [4]. Such distress is related with the asphalt- cement binder and can be controlled essentially by modifying the binder material with chemical additives, [5]. In Iraq under the impact of heavy traffic loading, moisture damages and high temperature, specific requirements are expected to control the material quality of highway pavement in order to increase the durability, [6].
Accordingly and to accomplish a reliable assessment of the asphalt pavement rutting, one must consider material, loading and environmental factors at which permanent distortion accumulate for finding out pavement layer. Furthermore, conditions experimental tests which satisfactorily simulate the field conditions could also be considered. In particular, the issue of development of performance tests and measure of rutting performance with regard to Mechanistic Empirical approach has become the focus of current research.

To achieve the main goals of this study, available local materials are used consisting of asphalt binder, aggregates, mineral filler and additive contents. Asphalt binders of (40-50 or PG 64-16) and (85-100 or PG 5822) from Al-Daura refinery in Baghdad were obtained, and the aggregate from Al-Nibaie quarry whereas the mineral filler brought from lime factory in Karbala, the additive used in this study is SBR polymer (Styrene Butadiene Rubber) is brought from Najaf Tyres Factory in Iraq. The Superpave mix design is adopted with varying volumetric compositions. The Superpave Gyratory Compactor SGC was utilized at the NCCL laboratory for preparing 24 cylindrical specimens of asphalt concrete of (15 cm diameter and $14.5 \mathrm{~cm}$ height) for carrying out volumetric design criteria. For proof testing the ability of HMA to resist permanent deformation, Wheel Tracking devices have gained a great consideration as potential candidates during the

\footnotetext{
* Corresponding author: Zaynab.2010@yahoo.com
} 
implementation phase of Superpave. It is considered the most widely used simulative test, the rut depth criteria for the WTT test were developed by AASHTO TP-63 for its employment, [7]. The basic principle of WTT is to simulate the stress conditions during which 108 slab samples were tested under repeated, moving-wheel loads as they actually occur on in-service pavements.

For preparing the asphalt concrete slabs, Roller Wheel Compactor Machine has been locally manufactured to prepare slab specimens of $(32 \mathrm{~cm}$ length $\times 28 \mathrm{~cm}$ width $\times 4 \mathrm{~cm}$ height). The application of Mechanistic-Empirical approach is presented using MnPAVE, 2011 program and its output results with that of the developed models are compared. The Mechanistic-Empirical Pavement Design Guide MEPDG is developed under the NCHRP a project represents a major advancement to pavement design and analysis. It uses site specific traffic, climatic conditions and materials properties to predict rutting and cracking performance of flexible pavement structures, [8].

\section{Wheel tracking tests}

In this study, compacted asphaltic slabs are prepared at air voids equal to (4\%) using Roller Compactor Device according to (EN12697-Part 33:2003) and Superpave system (AASHTO Designation: $T$ 312-2010). The dimensions of the compacted slabs used in this work are $320 \mathrm{~mm}$ (12.8 inch) in length and $280 \mathrm{~mm}$ (11.2 inch) in width and $40 \mathrm{~mm}$ (1.6 inch) in height as proposed by (EN 12697-Part 22:2003), [9]. Proportion of aggregate and asphalt binder are used for mixing, curing, and compacting, [10]. The fractions of aggregate are separated into nine sizes, as retained on each of the conventional sieves.

The desired mineral filler or Limestone is added according to the gradation requirements. The aggregate was combined into batch of (9700 $\mathrm{g}$ for slab specimen) in the mixing bowl and heated to the mixing temperatures prior to mixing with heated asphalt corresponding to each binder. Mixing and compaction temperatures for both types of asphalt binder were determined using Superpave Rotational viscometer, it were $160 \pm 3^{\circ} \mathrm{C}, 146 \pm 4{ }^{\circ} \mathrm{C}$ for asphalt binder PG (6416) grade and $152 \pm 2^{\circ} \mathrm{C}, 140 \pm 5^{\circ} \mathrm{C}$ for asphalt binder $\mathrm{PG}$ (58-22).

\section{Results and analysis}

In this study outcomes of the wheel tracking test were plotted on a diagram showing rut depth (normally in millimetres) versus the number of passes for each test. A curve is plotted for the loaded wheel for the test running, an examination of the graph can reveal the number of passes to failure, the maximum rut depth occurring. The rut depth development monitored with an automatic displacement measuring device by setting the machine motion and taking readings of the vertical displacement initially, r0, and then after every $(25 \pm 1)$ load cycles. The tracking is continuing for 10000 load cycles or until a rut depth of $25 \mathrm{~mm}$ is reached, whichever is shorter. The maximum rut depth for loaded wheel is displayed prominently along with a box declaring whether the test passed or failed. The experiment design for the rutting test is a full factorial with; three asphalt contents, two asphalt types, two air voids contents, three temperatures, and three percent of SBR additives, resulting in a nominal total of 108 tests. Based on results and analysis of permanent deformation tests, Table 1 summarizes and provides a qualitative description of the Influence of Temperature, Performance Grade and Mix Components on Plastic Parameters. As shown in this Table the permanent deformation is highly dependent on temperature, Performance grade and air voids, while moderate and low for polymer content and asphalt content respectively.

Table 1. Influence of Different Parameters on Plastic Parameters

\begin{tabular}{|c|c|c|c|c|c|}
\hline \multicolumn{2}{|c|}{ Variable } & $\begin{array}{c}\text { Rut } \\
\text { Depth, } \\
\mathrm{mm}\end{array}$ & $\begin{array}{c}\text { TR, } \\
\mu \mathrm{m} / \\
\text { cycl } \\
\mathrm{e}\end{array}$ & $\begin{array}{c}\text { WTR } \\
, \mu \mathrm{m} / \\
\text { cycle }\end{array}$ & $\begin{array}{c}\text { WTS } \\
\mathrm{mm} / \\
10^{3} \\
\text { cycles }\end{array}$ \\
\hline \multirow{2}{*}{ Temp., ${ }^{\circ} \mathrm{C}$} & 40 to55 & 19.44 & 9.4 & 9.7 & 14.65 \\
\cline { 2 - 6 } & 55 to 70 & 30.46 & 26.2 & 26 & 34.58 \\
\hline $\begin{array}{c}\text { Asphalt } \\
\text { Content, } \%\end{array}$ & 4.1 to4.7 & -8.25 & -32 & -33 & -24 \\
\cline { 2 - 6 } & 4.7 to5.3 & 19 & 67 & 68 & 31 \\
\hline $\begin{array}{c}\text { Performan } \\
\text { ce Grade }\end{array}$ & $\begin{array}{c}\text { PG58-22to } \\
\text { PG } 64-16\end{array}$ & -30 & -25 & -26 & -29 \\
\hline $\begin{array}{c}\text { Air Voids } \\
\text { Content, } \%\end{array}$ & 4.0 to 7.0 & 56 & 73 & 74 & 96 \\
\hline $\begin{array}{c}\text { Polymer } \\
\text { SBR }\end{array}$ & 0 to 1.5 & -23 & -17 & -17 & -28 \\
\cline { 2 - 6 } Content, $\%$ & 1.5 to 3 & -9 & -8 & -8 & -12 \\
\hline
\end{tabular}

\section{Statistical models}

The statistical techniques are used for the model development required for evaluating permanent deformation in asphalt concreting mixtures. In statistical modelling, the overall objective is to develop a predictive equation correlate the permanent deformation in the form of permanent strain with the independent variables. These variables include number of passes, asphalt grade, air voids, asphalt content, testing temperature, and additive content.

Numerous studies have been made to characterize the permanent deformation response of asphalt concrete materials due to repeated load applications, [11]. The repeated compressive load test is used to investigate the variables that influence the relationship between the number of load applications, $(\mathrm{N})$, and the permanent strain, ( $\varepsilon p)$. For this research, relationship between the permanent deformation in terms of plastic strain ( $\varepsilon p)$ of asphalt concrete mixtures is presented in equation (1):

$$
\varepsilon p=R D / h
$$

Where: $\varepsilon p=$ Vertical Permanent Strain at Mid Thickness (h) of the Layer, (\%), 
$\mathrm{RD}=$ Rut Depth at $(\mathrm{N})$ Number of Load Cycles (mm), and, $\mathrm{h}=$ Thickness of Asphalt Concrete Sublayer.

Analysis of results, calculation of standard error, coefficient of variation for the permanent strain ( $\varepsilon p$ ), permanent deformation (RD) and allowable number of repetitions $(\mathrm{Nf})$ models are presented in Table 2 .

Table 2. Summary Results of Final Models

\begin{tabular}{|c|c|c|}
\hline Model & $\mathbf{R}^{2}$ & SER \\
\hline $\begin{aligned} \mathrm{RD}= & 2.335 \mathrm{LnN}+5.752 \mathrm{Ln} \mathrm{P}_{\text {Seff. }}+ \\
& 9.73 \mathrm{LnT}-0.309 \mathrm{LnP} \mathrm{M}_{\mathrm{M}}-28.02 \\
& \eta+1.789 \mathrm{~A}_{\mathrm{v}}-49.68\end{aligned}$ & 0.88 & 0.231 \\
\hline $\begin{array}{c}\varepsilon_{\mathrm{p}}=0.058 \mathrm{LnN}+0.144 \mathrm{Ln} \mathrm{P}_{\text {Seff. }}+ \\
0.243 \mathrm{LnT}-0.008 \mathrm{Ln} \mathrm{P}_{\mathrm{M}^{-}} \\
0.701 \eta+0.045 \mathrm{~A}_{\mathrm{v}}-1.242\end{array}$ & 0.88 & 0.231 \\
\hline $\begin{array}{r}\mathrm{N}_{\mathrm{f}}=7.23 * 10^{6} * \mathrm{RD}^{2.476 * \mathrm{P}_{\mathrm{Seff}}{ }^{-1.031} *} * \\
\mathrm{~T}^{-1.947 * \mathrm{P}_{\mathrm{M}}} \cdot{ }^{0.06} * \eta^{2.411} * \mathrm{~A}_{\mathrm{v}}{ }^{-1.7}\end{array}$ & 0.89 & 0.207 \\
\hline
\end{tabular}

\section{Mechanistic-empirical approach}

\section{analysis}

The NCHRP 1-37A project conveyed the latest M-E based strategy that fuses broadly adjusted models to anticipate distinct distresses instigated by traffic load and weather conditions. The NCHRP 1-37A methodology likewise joins vehicle class and load distributions in the design plan, a stage forward from the Equivalent Single Axle Load (ESAL) approach utilized as a part of the AASTHO design equation and different methods, [8].

M-E design methods depend on the mechanics of materials that relate input information, for example, wheel load and material properties to an output of pavement reaction, for example, stress or strain. In the M-E Design Guide method, the asphalt pavement is viewed as a multi-layered elastic system. The materials in each of these layers were described by modulus of Elasticity $\left(E^{*}\right)$ and Poisson's ratio (v).

This technique requires the determination of critical stress, strain, or deflection in the asphalt pavement by some mechanistic method and the estimation of resulting damages by some empirical failure criteria before the thickness design and remaining life of the current pavement which will be assessed. In the M-E design process, the multi-layer structure is analysed mechanistically to evaluate the critical strains created within the structure. These values of strain are utilized to appraise the structural capacity in terms of repeated traffic loading by utilizing the empirically derived transfer functions.

The outcomes are compared with the results obtained from laboratory based statistical models and field section cores to validate the mechanistic component of asphalt concrete mixtures. Powell and Leech in 1983 showed that the dynamic stiffness of the mixture increases by 30 $\%$ if the void content of the material is reduced by $3 \%$. Linear elastic analysis of the construction as a whole shows that, by reducing void content, the thickness of the construction can be reduced by $8 \%$, [12].
The other advantage of adequate compaction is the increase in the resistance to the permanent deformation. An increase of 3\% in compaction leads to a reduction of the permanent deformation of about $50 \%$ after 1000 passes, measured with a pneumatic tyre wheel tracking machine, [13].

On account of the perpetual flexible pavement enough stiffness in the upper pavement layers is expected to keep away from rutting and enough total pavement thickness and flexibility in the lowest layer to oppose fatigue cracking from the pavement structure bottom. Since the HMA pavement is tailored to oppose specific distresses in each layer, the materials selection, mix design, and performance testing should be specialized for every material layer.

\section{Application of MnPAVE program}

MnPAVE is a computer program developed through a joint effort by the Minnesota Department of Transportation and the University of Minnesota version 6.1 on October, 2011. MnPAVE combines known empirical relationships with a portrayal of the mechanics and physics behind flexible pavement behaviour. The mechanistic portions of the program depend on finding the tensile strain at the asphalt layer bottom, the compressive strain at the top of the subgrade, and the maximum principal stress in the middle of the aggregate base layer.

MnPAVE comprises of three information modules: Traffic, Climate, and Structure, and three design levels: Basic, Intermediate, and Advanced. The level is chosen based on the amount and quality of information known about the material properties and traffic data.

Material information consists of layer thickness, Poisson's ratio, dynamic modulus, and an index indicating the slip degree among layers. MnPAVE assumes zero slip at all layer interfaces. Other inputs include load and evaluation locations. Loads are characterized by pressure and radius. MnPAVE output includes expected life of the pavement and the damage factors. Reliability also has been incorporated into the latest version.

The M-E PDG requires an expansive arrangement of material properties. Three parts of the design procedure require material properties: the climate model, the pavement response models, and the distress models. Climate related properties are utilized to investigate temperature and moisture variations inside the pavement structure. To process the state of stress/strain at critical locations in the structure due to traffic loading and temperature changes; rectified as suitable for temperature and moisture impacts; the models of pavement response uses material properties. These structural responses were utilized by the distress models along with correlative material properties to predict pavement performance.

The asphalt concrete dynamic modulus defined as one of the material properties required in the M-E PDG which is considered innovative for pavement design methods. Temperature dependency and Loading time of 
asphalt mixtures are characterized by the dynamic modulus, $\left|\mathrm{E}^{*}\right|$. The dynamic modulus master curve models the variation of asphalt concrete stiffness because of the rate of loading and temperature variation (hardening with low temperature/high frequency and softening with high temperature/low frequency). The non-linear elastic behaviour of unbound granular materials is modelled by a stress-dependent resilient modulus included as factors input. The complex dynamic modulus $\left|E^{*}\right|$ is the principal material property input for asphalt concrete.

It is a function of mixture characteristics: (binder, gradation of aggregate and volumetric properties), temperature, age, and rate of loading. For information, the dynamic modulus master curve is constructed based on time-temperature superposition principles by shifting laboratory frequency sweep test data, [14] and [15].

Binder viscosity measured using the Superpave Rotational Viscometer (RV) is also a required input. For inputs, the dynamic modulus master curve is developed in view of an empirical predictive equation. The $\left|E^{*}\right|$ predictive equation is an empirical relationship between $\left|\mathrm{E}^{*}\right|$ and mixture properties as shown below:

$\log E^{*}=3.750063+0.02932 . \rho_{200}-0.001767 .\left(\rho_{200}\right)^{2}$
$-0.002841 . \rho_{4}-0.058097 . V_{a}-0.802208 .\left(\frac{V_{b e f f .}}{V_{b e f f .}+V_{a}}\right)+$

$\underline{3.871977+0.0021 . \rho_{4}+0.003958 . \rho_{38}-0.000071 .\left(\rho_{38}\right)^{2}+0.005470 . \rho_{34}}$ $1+e^{(-0.603313-0.313351 . \log (f)-0.393532 . \log (\theta))}$

Where: $\mathrm{E}^{*}=$ dynamic modulus, $105 \mathrm{psi}$;

$\eta=$ binder viscosity, 106 Poise;

$\mathrm{f}=$ loading frequency, $\mathrm{Hz}$;

$\mathrm{Va}=$ air void content, $\%$;

$\mathrm{V}_{\text {beff }}=$ effective binder content, $\%$ by volume;

$\rho 4=$ cumulative $\%$ retained on the $4.75-\mathrm{mm}$ sieve;

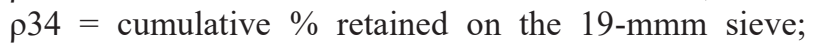
$\rho 200=\%$ passing the $0.075-\mathrm{mmm}$ sieve;

$\rho 38=$ cumulative $\%$ retained on the $9.5-\mathrm{mm}$ sieve.

\subsection{Binder viscosity values}

The binder's viscosity values used in this research are estimated utilizing the ASTM viscosity-temperature equation (NCHRP Report 1-37A, 2004), given by the relationship as equation (3):

$$
\log \log \eta=A+V T S^{*} \log T R
$$

In which:

$\eta=$ bitumen viscosity, $\mathrm{cP}$;

$\mathrm{A}=$ regression intercept;

$\mathrm{TR}=$ temperature, Rankine $(\mathrm{TR}=\mathrm{T}$ Fahrenheit +460$)$;

$\mathrm{VTS}=$ regression slope of viscosity temperature susceptibility.

The values of viscosity for binders and test temperatures relevant to this study are presented in Table 3.
Table 3. Binder Viscosity According to ASTM ViscosityTemperature Relationship

\begin{tabular}{|c|c|c|}
\hline Binder Grade & $\begin{array}{c}\text { Test } \\
\text { Temperature }\end{array}$ & $\begin{array}{c}\text { Viscosity, } \\
\text { Pa.sec }\end{array}$ \\
\hline PG 64-16 & $40^{\circ} \mathrm{C}$ & 2.87 \\
\hline PG 64-16 & $55^{\circ} \mathrm{C}$ & 2.25 \\
\hline PG 64-16 & $70^{\circ} \mathrm{C}$ & 1.79 \\
\hline
\end{tabular}

\section{MnPAVE results and data analysis}

The recent software provides capabilities for the analysis and performance prediction of various input parameters for local conditions. In MnPAVE, the Research Mode provides the components important to finish an asphalt pavement design, more features in entering information. The allowed repetitions for rutting were determined by simulating the strains because of traffic loads, according to equation (4):

$$
N R=K_{R 1} \varepsilon v^{K R 2}
$$

Where: NR $=$ number of repetitions to rutting failure (Allowed Repetitions), cycle KR1, KR2 = MnPAVE coefficients $\varepsilon \mathrm{V}=$ vertical strain at the top of the subgrade (in/in) In order to evaluate the effect of input variability on the calculated reliability; the influence of binder type, air voids, binder content and temperature on dynamic modulus is evaluated, as described in the following articles :

\subsection{Effect of air voids}

One of the essential parameters which have a pivot role on the performance of asphalt pavement is air voids. At two levels of air voids; the dynamic modulus of asphaltic mixture is evaluated: (a) $7 \%$ air voids level and (b) $4 \%$ air voids level with binder of PG (64-16) and temperatures of $40^{\circ} \mathrm{C}, 55^{\circ} \mathrm{C}$ and $70^{\circ} \mathrm{C}$. The results are shown in Figure 1. It is found that increasing of air voids from $4 \%$ to $7 \%$ will decrease $E^{*}$ and reliability by $11.2 \%$ and $12 \%$ respectively for asphalt of PG (64-16). Figure 2 show that reliability value of $93 \%$ is reached for rutting and the allowable repetitions of loading greater than 8300 cycle through running of verification; so this design is conservative. Same behaviour can be achieved for the other type of asphalt binder.

\subsection{Effect of asphalt binder type}

One of the basic components in asphaltic mixtures is asphalt binder. The performance of an asphalt mixture is straightforwardly identified with binder mechanical characteristics. Subsequently, there is a need to assess the relationship between the binder's properties and 
asphaltic mixtures such that an appropriate comprehension and selection of an asphalt binder can be made to enhance the asphaltic mixture performance. In this study, the impacts of asphalt binder properties on asphalt mixtures at various temperatures were assessed. Figure 3 shows the comparison of two types of binders; PG (64-16) and PG (58-22), High temperature and low frequency related with the rutting resistance of the asphalt mixture. The outcomes demonstrate that the PG grade, particularly the high PG grade impacts the dynamic modulus at high temperature; higher PG grade leads to higher $\mathrm{E}^{*}$. It is found that a change of binder of PG (64-16) to PG (58-22) causes 5.5\% decrease in $\mathrm{E}^{*}$ and $20 \%$ decrease in reliability at $40^{\circ} \mathrm{C}$ testing temperature. Figure 4 shows that reliability value of $93 \%$ is reached for rutting and the allowable repetitions of loading greater than 8300 cycles for PG (64-16).

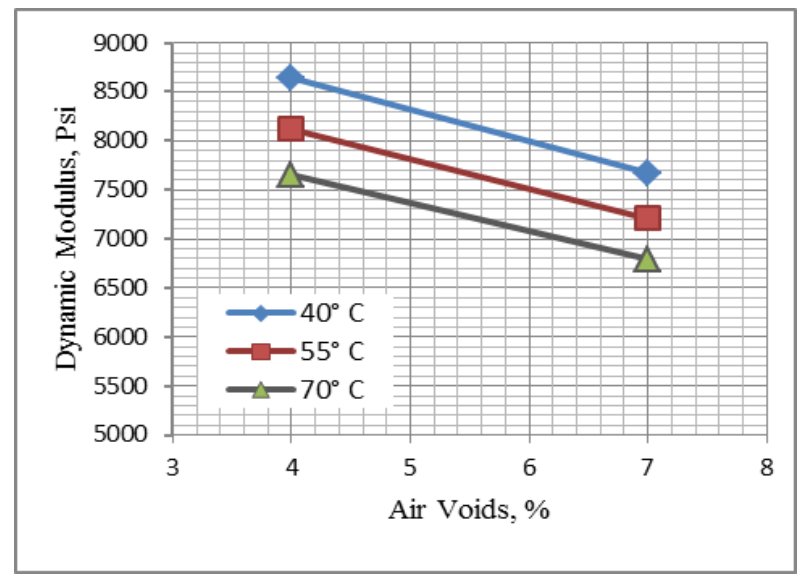

Fig. 1. Effect of Air Voids on Dynamic Modulus for PG (6416)

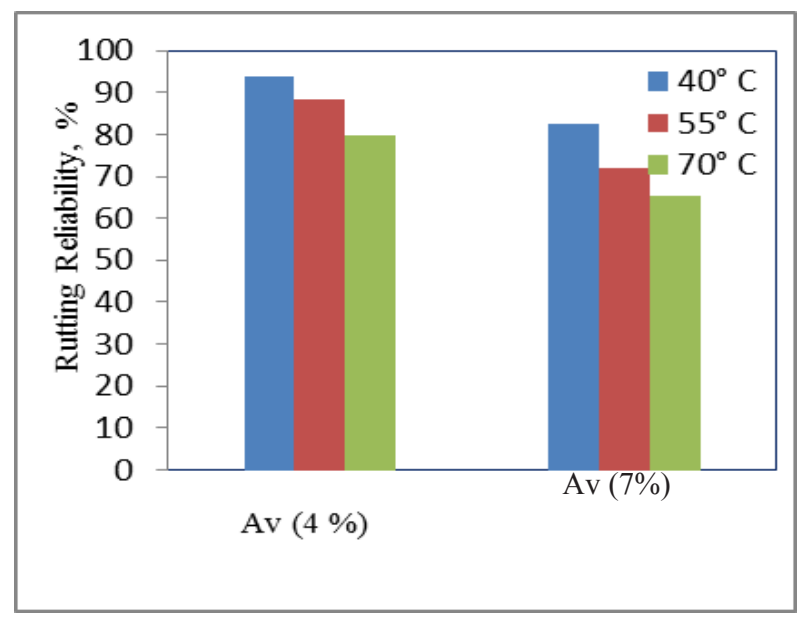

Fig. 2. Effect of Air Voids on Reliability

\subsection{Effect of asphalt content}

The effect of asphalt content on Dynamic modulus was evaluated; Figures 5 and 6 show the comparison of dynamic modulus and reliability for three various asphalt contents. It is noted that the increase of asphalt content from $4.1 \%$ to $4.7 \%$ causes $4.9 \%$ decrease in $\mathrm{E}^{*}$ at $40^{\circ} \mathrm{C}$

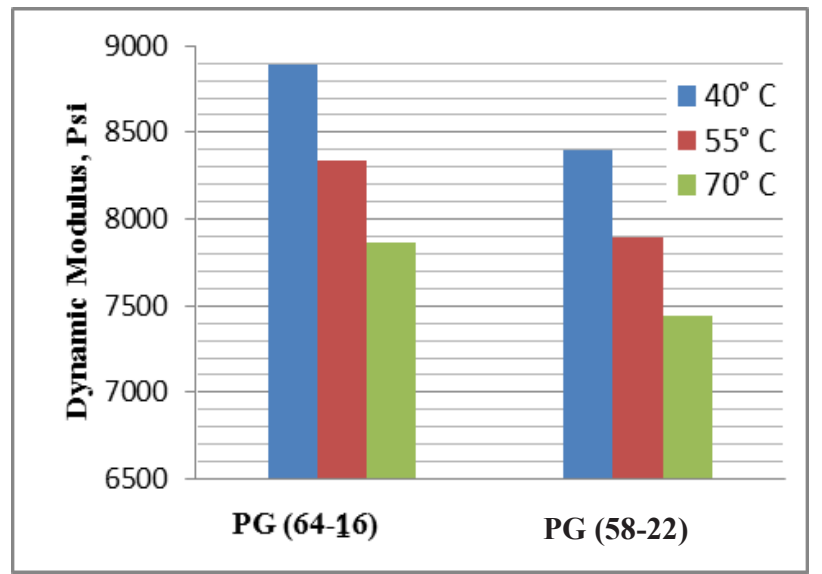

Fig.3. Effect of Asphalt Binder Type on Dynamic Modulus

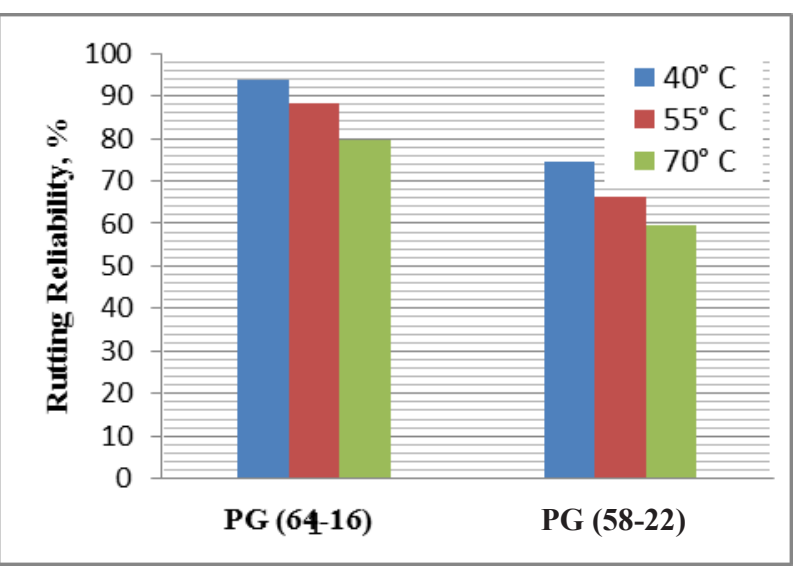

Fig.4. Effect of Asphalt Binder Type on Reliability

test temperature, while an increase of asphalt content from $4.7 \%$ to $5.3 \%$ causes $5.5 \%$ decrease in $\mathrm{E}^{*}$ at $70^{\circ} \mathrm{C}$ test temperature. It is viewed as that the asphalt binder is softer and less influential regarding the load bearing capacity at high temperatures; rather, aggregate skeleton assumes a more important part. Asphalt content has some effect on $\mathrm{E}^{*}$ and allowable number of repetitions.

\section{Comparisons between the laboratory model and MnPAVE results}

A comparison between the structural performances of MnPAVE software results with Superpave laboratory model is carried out. The pavement volumetric and mechanical properties were used as an input data for MnPAVE Software.

The WTT allowable number of repetitions results for rutting performance of mixtures utilized in this research and developed for various degree of test temperatures are compared with MnPAVE results. Figures 7 to 9 show the relationships between WTT's allowable number of repetitions model which was developed previously and stated in Table 3, Good relationship can be observed unmistakably between these two types of outcomes. 


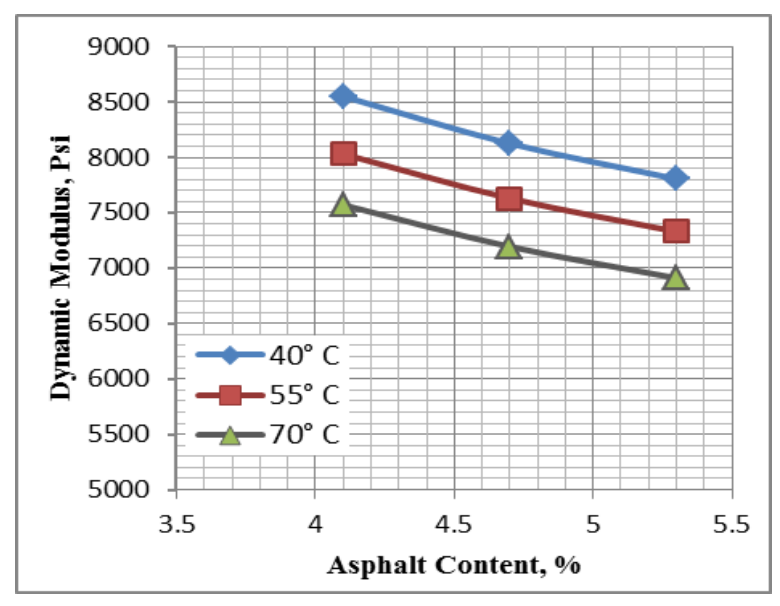

Fig.5. Asphalt Content with Dynamic Modulus

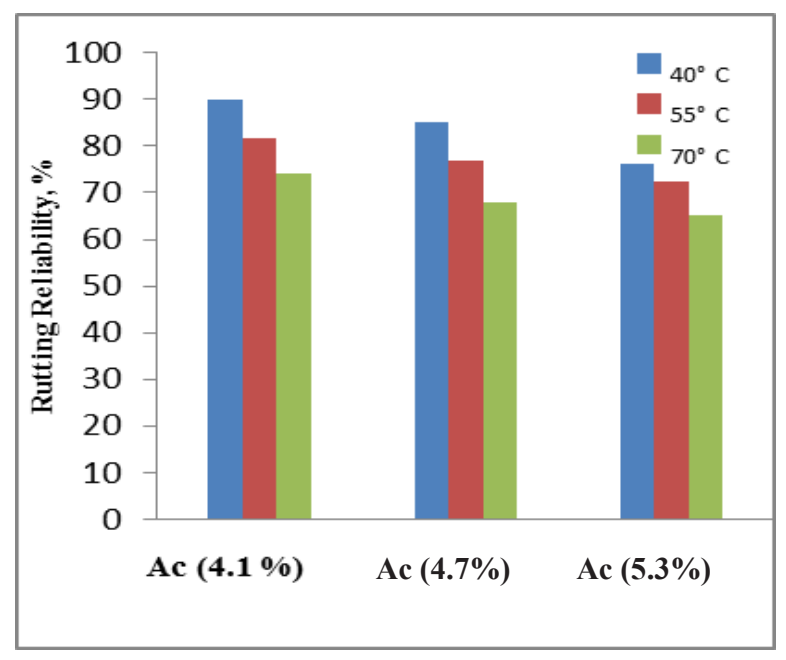

Fig. 6. Asphalt Content with Reliability

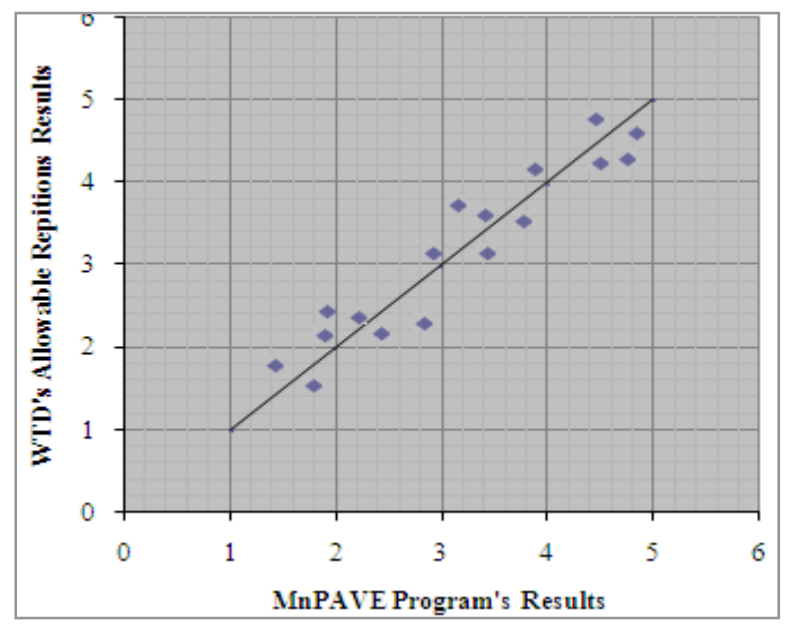

Fig. 7. WTT's Allowable Repetitions vs. MnPAVE Results at $40^{\circ} \mathrm{C}$

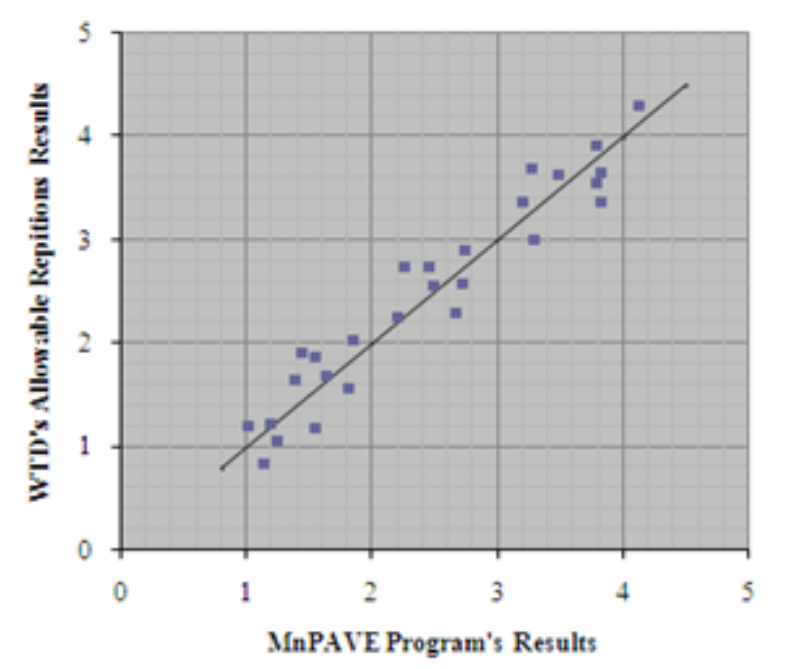

Fig. 8. WTT's Allowable Repetitions vs. MnPAVE Results at $55^{\circ} \mathrm{C}$

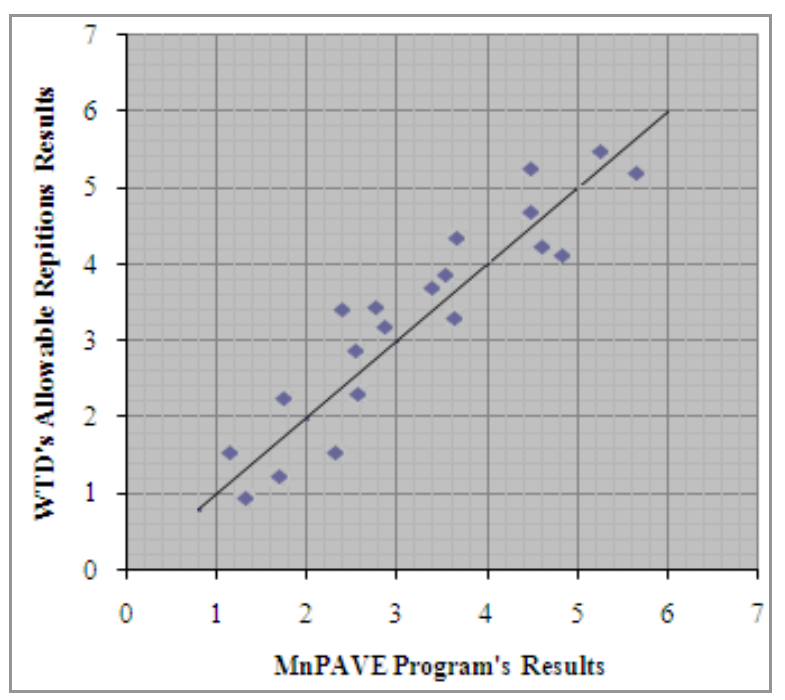

Fig. 9. WTT's Allowable Repetitions vs. MnPAVE Results at $70^{\circ} \mathrm{C}$

\section{Conclusions}

In light of wheel-track test comes about, a model was developed to predict permanent strain of local asphalt concrete mixtures of wearing course after short- term aging mixtures for different mix properties and test conditions utilizing statistical technique, as equation 5:

$\varepsilon p=0.058 \operatorname{LnN}+0.14 \operatorname{Ln} P S+0.24 \operatorname{LnT}-0.008 \operatorname{LnPM}-$ $0.701 \eta s+0.045 A v-1.242$

Where: $\varepsilon p=$ Vertical Permanent Strain at Mid Thickness $(\mathrm{H})$ of the Layer; $\mathrm{N}=$ Number of Loading Cycles; PS = Effective Asphalt Content, (\%) by Weight of Total Mix; $\mathrm{T}=$ Test Temperature in Degree Centigrade $\left({ }^{\circ} \mathrm{C}\right) ; \eta \mathrm{s}=$ Viscosity at Testing Temperature (Pa.sec); Av = Air Void of Asphalt Mixtures (Av from 4.0-7.0 \%), and; PM = Additive (SBR- Polymer) Content, (\%) by Weight of asphalt binder. 
Mechanistic Empirical design approach through MnPAVE 2011 software, used to characterize rutting in HMA and to predict allowable number of loading repetitions as a function of expected traffic loads, material properties, and environmental conditions, has been employed to verify the developed model with satisfactory result. The influence of variables on dynamic modulus $\mathrm{E}^{*}$ and rutting reliability is evaluated. It is viewed that increasing of air voids from $4 \%$ to $7 \%$ causes a decrease $\mathrm{E}^{*}$ and reliability by $11.2 \%$ and $12 \%$ respectively for asphalt of PG (64-16). While a change of binder of PG (64-16) to PG (58-22) causes $5.5 \%$ decrease in $\mathrm{E}^{*}$ and $20 \%$ decreases in reliability at $40^{\circ} \mathrm{C}$ testing temperature. Furthermore, an increase of asphalt content from 4.1 to $4.7 \%$ causes $4.9 \%$ decrease in $\mathrm{E}^{*}$ at $40^{\circ} \mathrm{C}$ test temperature, while a change of asphalt content from 4.7 to $5.3 \%$ causes $5.5 \%$ decrease in $\mathrm{E}^{*}$ for $\mathrm{PG}$ (64-16).

The authors might want to recognize the National Centre for Construction Laboratories (NCCL) and the College of Engineering of Baghdad University in Iraq for their support during the preparation of this research.

\section{References}

1. K. P. Khosla, V. Kadayam, K.I. Harikrishnan, FHWA/NC/2002-030, Final Report Submitted to NCDOT, (2007).

2. J.S. Miller, W.Y. Bellinger, Final Report Submitted to U.S. Transportation Dep., FHWA-RD-03-031, (2003).

3. Y. Huang, Pavement Analysis and Design, 2nd Edition Prentice Hall College Div, New Jersey, USA. (1993).

4. R. Garba, Norwegian university of Science and Technology, NVF conference, 28 June-2 July, Reykjavik, Iceland, (2000).

5. H. Hamdou, N. Ahmed, Z. I. Qasim, IMS/7 International Conference on Advances in Engineering Materials, UAE, (2014).

6. Z. Qasim, A. Abbas, Z. Qasim, NJES, 20 pp.183 193, (2017).

7. AASHTO Guide for Design of Pavement Structures, Washington, D. C., USA. (2010).

8. C. Olidis, D. Hein, NCHRP Final Report ERES Consultants Division, Quebec, (2004).

9. European Standards EN 12697: CEN/TC 227 "Road materials", August. (2005).

10. Asphalt Institute, Asphalt Hand Book, Six Edition, Kentucky, USA. (2007),

11. M. Fattah, K. Al Helo, Z. Qasim, RMPD Journal, DOI: $10.1080 / 14680629.2015 .1119711$, Taylor and Francis Group, (2015).

12. W. Powell, D. Leech, Transport Research Laboratory, Crowthorne, LR 1102, (1983).
13. H. Henny, A. André, Civil Engineering \& Management Department, University of Twente, Netherlands, 7500 AE. (2000).

14. Y. Huang, Pavement Analysis and Design, $2^{\text {nd }}$ Edition, Prentice Hall, Englewood Cliffs, New Jersey, USA, (2004).

15. T. Pellinen, J. Song, S. Xiao, $8^{\text {th }}$ Conference of Asphalt Pavements in South Africa, CAPSA-04, September 12-16. (2004). 